\title{
Atomic structure of Co92-xBxTa8 glassy alloys studied by ab initio molecular dynamics simulations
}

\author{
Di Ma ${ }^{1}$, Jing Zhang ${ }^{1}$, Yaxin $\mathrm{Di}^{1}$, Jianfeng Wang ${ }^{1}$, Shaokang Guan ${ }^{1}$, and Tao Zhang ${ }^{2}$ \\ ${ }^{1}$ Zhengzhou University \\ ${ }^{2}$ Beihang University
}

April 28, 2020

\begin{abstract}
The ab initio molecular dynamics simulations are performed to study the atomic structures of Co92-xBxTa8 ( $\mathrm{x}=30,32.5$, 35, 37.5, at.\%) glassy alloys. The result shows that the local packing of B-centered clusters is more efficient than that for Coand Ta-centered clusters. It is also found that B-centered clusters are the primary structure-forming clusters. The Kasper polyhedra with a Voronoi index of $<0360>$ and $<0280>$ are dominant in B-centered clusters. Specially, the $<0360>$ clusters can form a robust network structure, which plays a key role in mechanical properties. Such a network structure has a higher activation barrier for structural rearrangement and a better resist to plastic flow. Thus, the increase in the fraction of $<0360>$ with B content would result in an increase in yield strength as well as a sharp decrease in compression plasticity.
\end{abstract}

\section{Hosted file}

Manuscript.docx available at https://authorea.com/users/306862/articles/437975-atomic-structureof-co92-xbxta8-glassy-alloys-studied-by-ab-initio-molecular-dynamics-simulations 


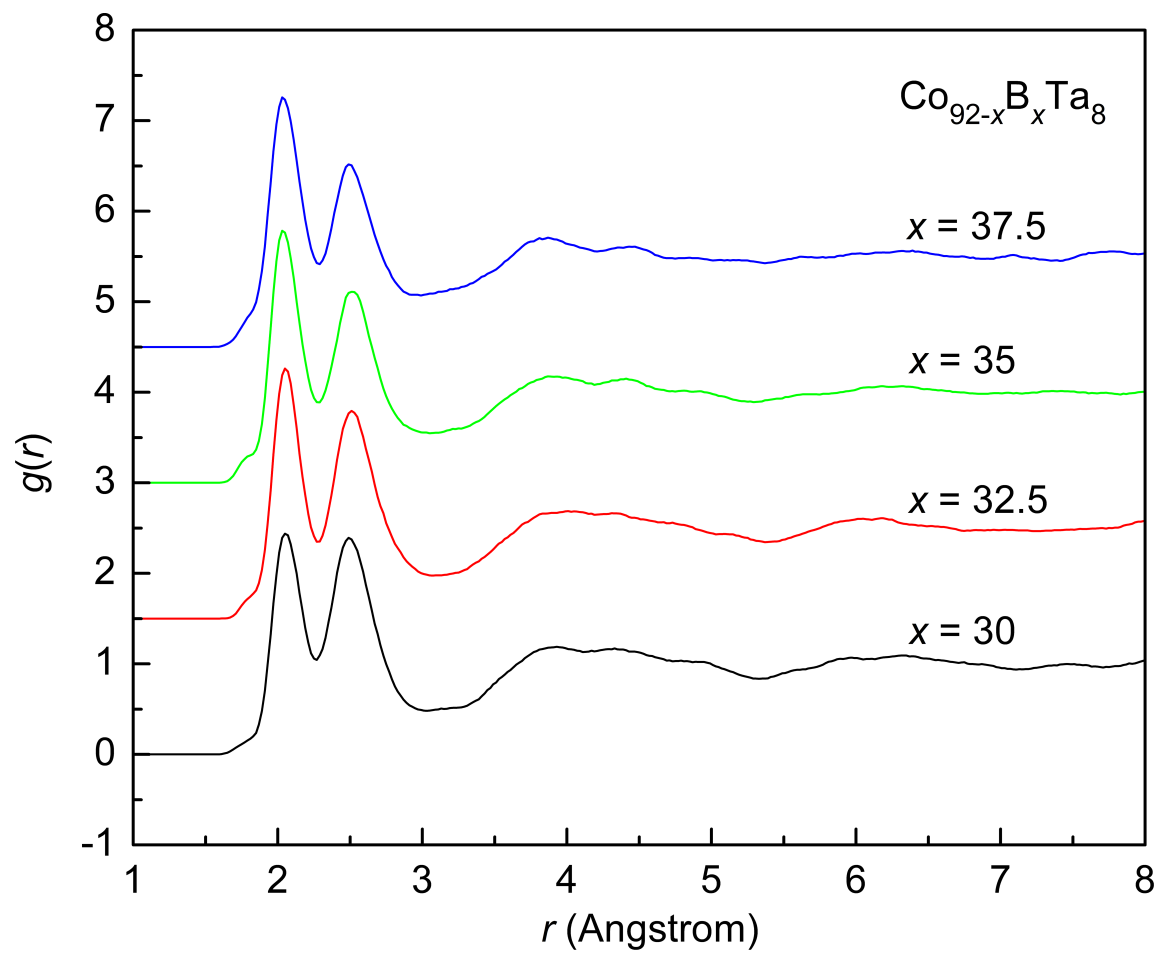



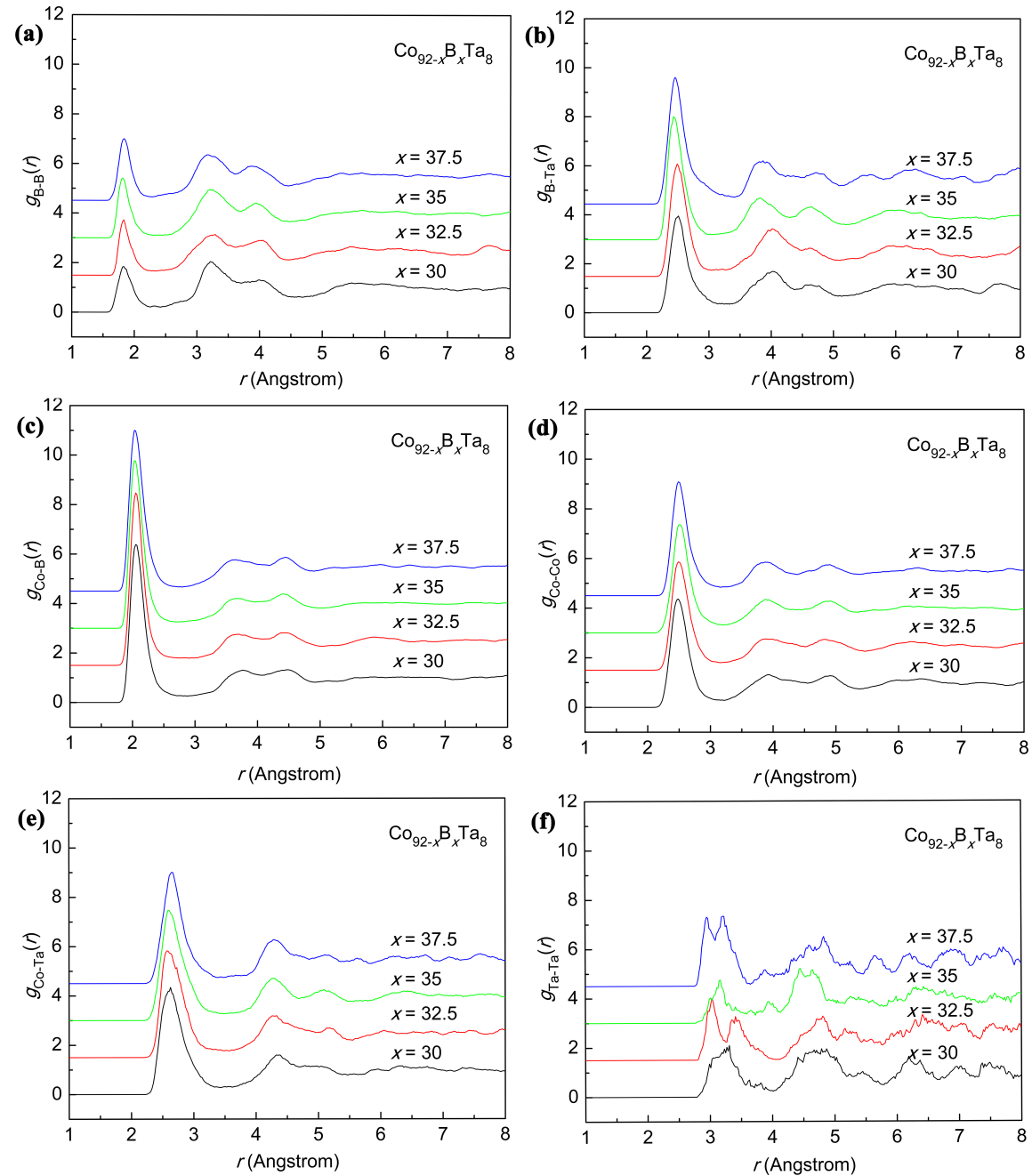

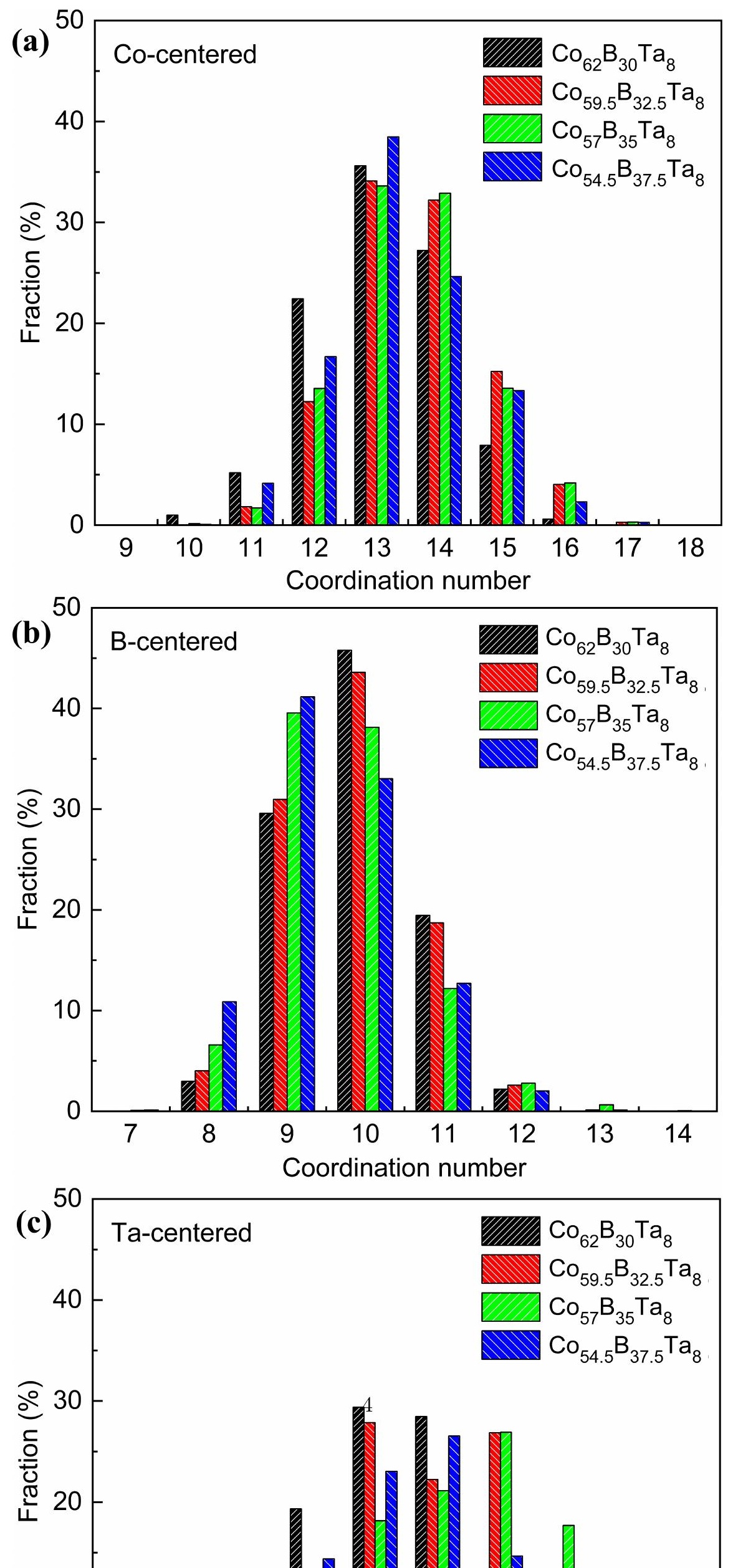

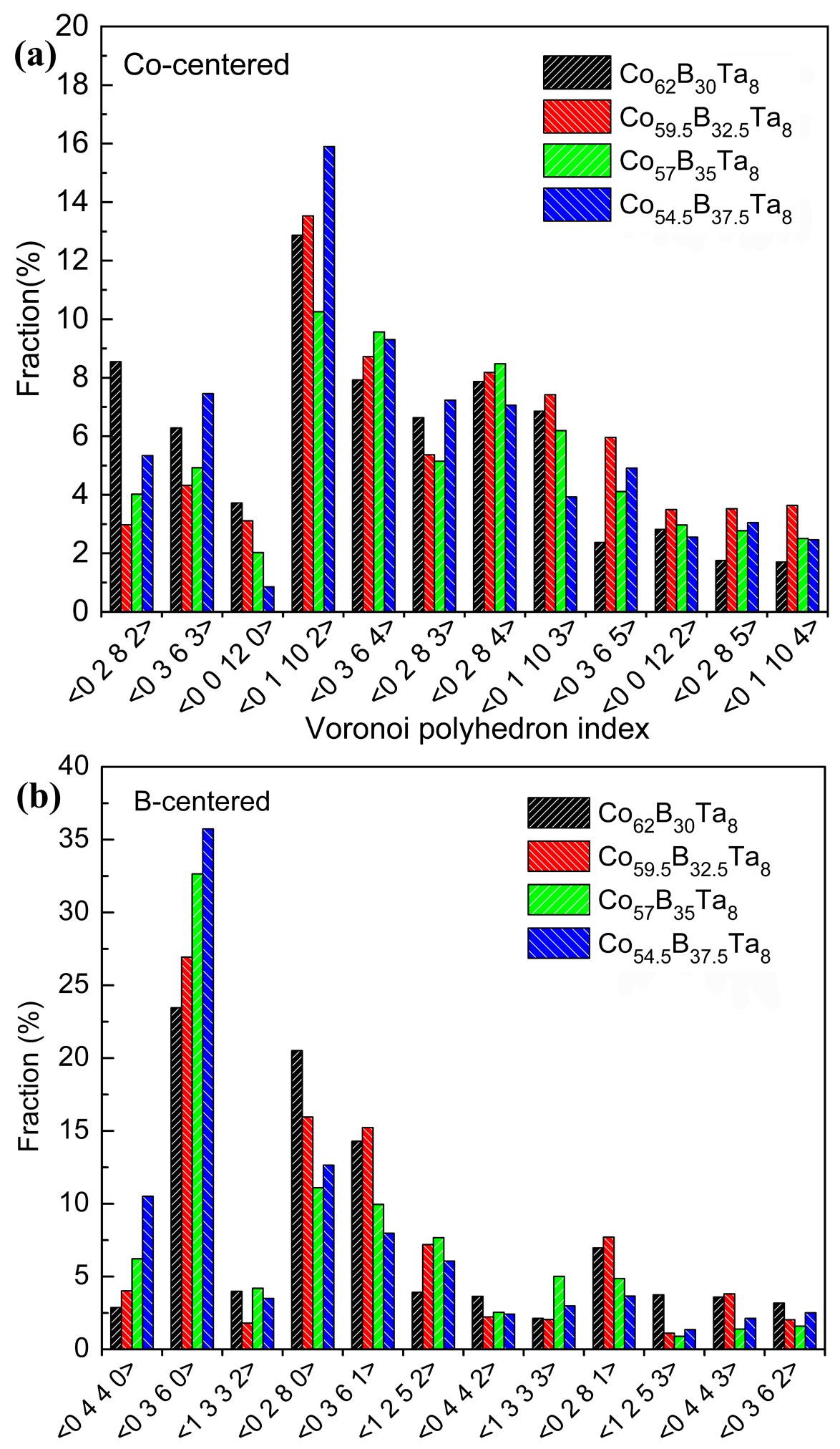

Voronoi polyhedron index

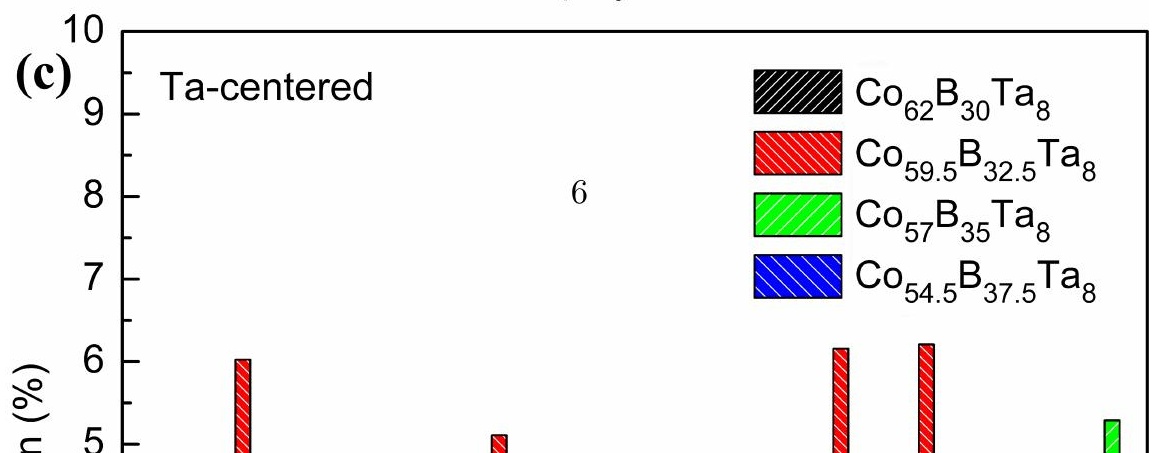




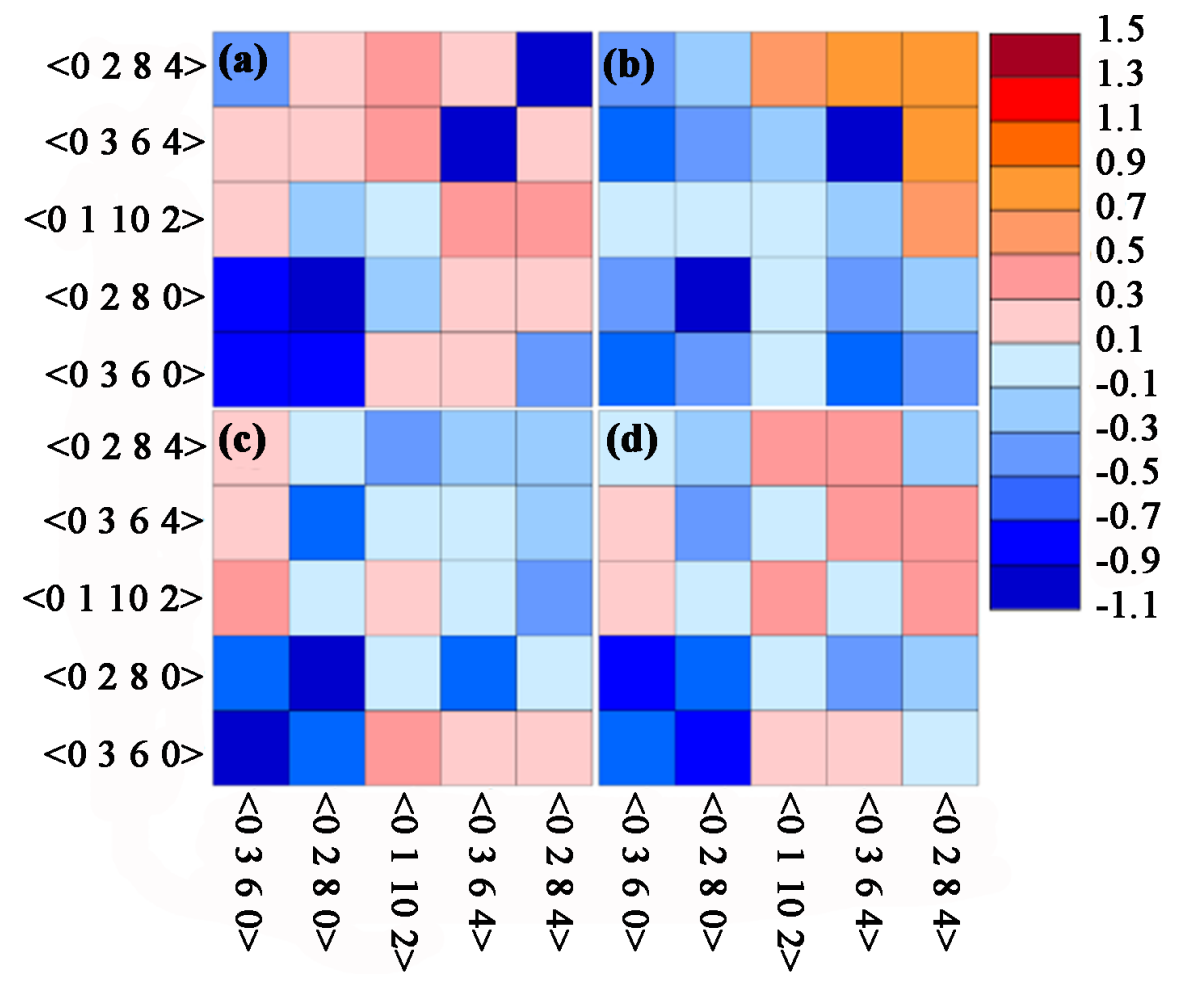

(a)

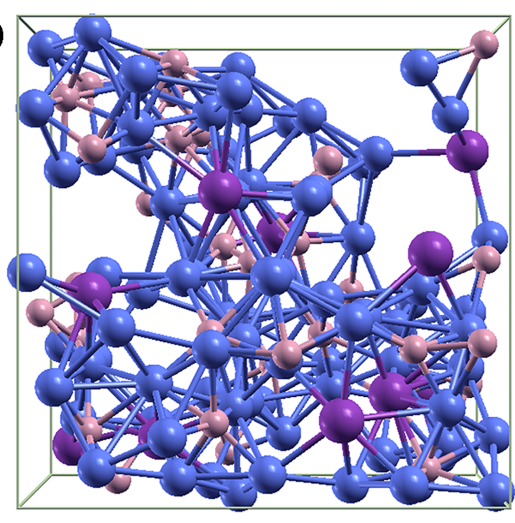

(c)

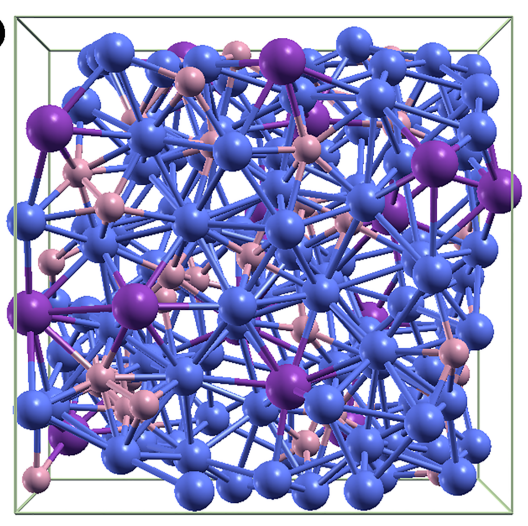

(b)

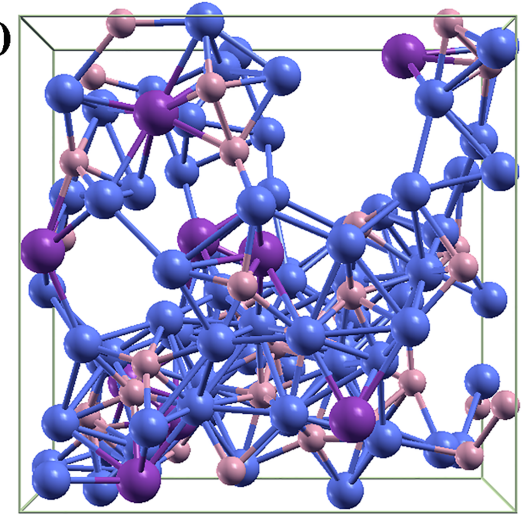

(d)

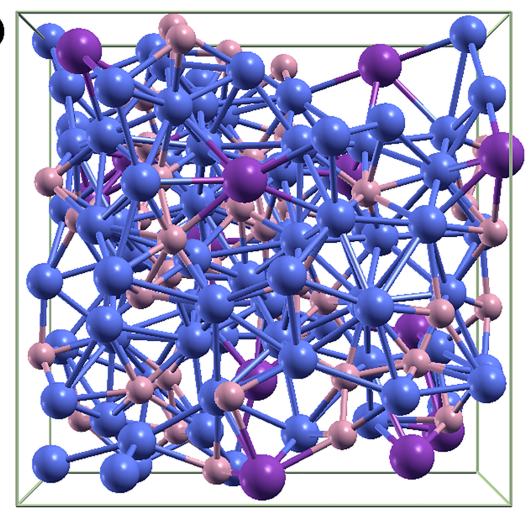




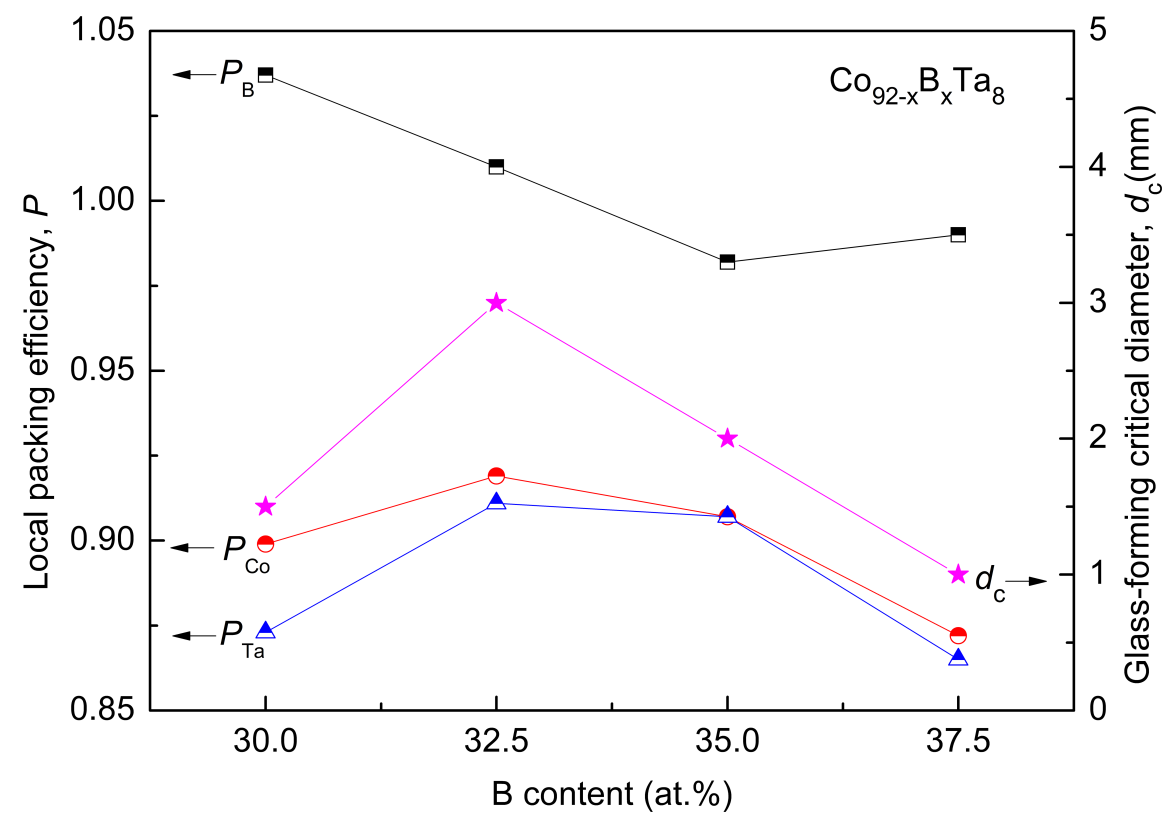

